\title{
A RISK MANAGEMENT METHODOLOGY FOR NON-METALLIC PROCESS EQUIPMENT
}

\author{
J.J. Viviers ${ }^{1}$ and J.K. Visser ${ }^{2}$ \\ ${ }^{1,2}$ Department of Engineering and Technology Management \\ University of Pretoria, South Africa \\ 1'viviers@sasol.co.za, ${ }^{2}$ krige.visser@up.ac.za
}

\begin{abstract}
Many companies in South Africa have implemented the risk-based inspection (RBI) methodology as a maintenance strategy. The risk involved in operating a piece of equipment, past history, non-destructive examination techniques, failure modes, and many other aspects determine the frequency of inspections required to meet legislation. The main purpose of the RBI methodology is to prevent failures of process equipment. The methodology for risk-based inspection for metal equipment is well-established and has been proven in industry, becoming the norm nationally and internationally. However, it is not possible to apply all the techniques to nonmetallic equipment owing to vast differences between the two types of materials. This paper discusses the results of data gathered on the RBI methodology for nonmetallic equipment, and proposes a risk-based model that can be used to perform a risk assessment for non-metallic equipment in a process plant. The risk assessment can be used to formulate the next inspection interval for the asset.
\end{abstract}

\section{OPSOMMING}

Verskeie maatskappye in Suid-Afrika het reeds die metodologie van risikogebaseeerde inspeksie (RBI) geïmplementeer as deel van ' $n$ omvattende instandhoudingstrategie. Die risiko betrokke by ' $\mathrm{n}$ fisiese item, bedryfsgeskiedenis, nie-vernietigende toetstegnieke, falingsmodusse, en vele ander aspekte bepaal die frekwensie van inspeksies wat benodig word om aan wetlike vereistes te voldoen. Die hoofdoel van die risiko-gebaseerde metodologie is om faling van prosestoerusting te verhinder. Die metodologie vir risiko-gebaseerde inspeksie van metaaltoerusting is goed bekend en word suksesvol toegepas in die industrie. Dis is egter nie moontlik om al die tegnieke toe te pas op nie-metaaltoerusting nie weens die groot verskeidenheid van materiaaltipes. Hierdie artikel bespreek die data wat ingewin is op die risiko-gebaseerde metodologie vir nie-metaaltipeprosestoerusting, en stel ' $n$ nuwe risiko-gebaseerde model voor wat gebruik kan word om die risiko te bepaal vir nie-metaal toerusting van 'n prosesaanleg. Die risikoprofiel kan gebruik word om die volgende inspeksie-interval vir die toerusting te formuleer.

\footnotetext{
${ }^{1}$ The author was enrolled for an M Sc (Applied Sciences) degree in the Department of Engineering and Technology Management, University of Pretoria.
} 


\section{Introduction}

The aim of risk management and risk-based inspection (RBI) is to identify flaws that can cause large-scale accidents before they actually occur. The risk-based inspection methodology is part of a maintenance management system, and the processes and models are aimed at top management as well as lower-level involvement. The methodology for risk-based inspection on metallic equipment is well established: it has been proven in industry, and has been adopted by many organisations across the world. The 'metallic' industry is mature, with various national and international standards and codes covering the design, manufacturing, installation, and maintenance of equipment. Some guidelines for using non-metallic pressure vessel equipment safely are provided in an amendment to the Occupational Health and Safety Act [1].

The current pressure vessel regulation will soon be replaced by a new Pressure Equipment Regulation (PER) [2]. The new legislation will include a definition for non-metallic equipment that includes any pipe, vessel, or tank containing hazardous or dangerous substances, even though the equipment may not be classified as a 'vessel under pressure'. Non-metallic equipment is used for the containment of hazardous and highly corrosive process media, and will thus be included under the new legislation. With this in mind, it is critical that the non-metallic industry has processes in place to meet the requirements of the new legislation.

Many specifications and industry standards have been developed to ensure the correct manufacturing and installation of equipment that is used in the chemical, process, paper, mining, and civil industries. Once standards are generated and equipment is installed accordingly, the next step for the end-user is to perform inspections to ensure the equipment's integrity and safe operation. It is in this phase of the life cycle that procedures, inspection criteria and information are very limited, and in many cases are not sufficient for the inexperienced engineer or enduser.

A research project was therefore initiated to contribute to this effort - to provide guidance when applying risk management principles to non-metallic equipment, and to identify any shortcomings in the process.

\section{RESEARCH OBJECTIVE}

The objective of this study was to provide the end-user of non-metallic equipment with a sound methodology to apply risk management principles to non-metallic equipment. Achieving the objective required a basic understanding of the materials. It was established that the current methodologies are not fully compatible with nonconventional materials such as non-metallics. The outcome of the research project was a qualitative approach to the risk assessment of non-metallic equipment used in the process industry. The methodology could be used as the basis for the development of a comprehensive risk-based inspection programme.

\section{LITERATURE REVIEW}

Tae-Gu et al. [3] researched the current risk management status of the Korean petrochemical industry, and also included statistics from the South African 
petrochemical industry. Major accident statistics from chemical plants for the years 1998-2000 were shown, reflecting the insured loss in millions. A loss of \$67 million was suggested for a typical South African chemical plant. This information indicates the importance and direct impact of this research on such industries in South Africa. Risk-based inspection is discussed in the research, and defined as a method that structurally synthesises the damage ratio and consequence of damage of pressure vessels and equipment in both quantitative and qualitative manners, and sets the priorities for testing and replacement timing.

The API 580 [4] recommended practice document on risk-based inspection addresses problems of a general nature with respect to particular circumstances. The API publications and codes are used as the basis of risk management for the metallic industry, and so were used as the basis of this research. The recommended practice is aimed at the hydrocarbon and chemical process industries. The purpose of this document is to provide users with the basic elements for developing and implementing a risk-based inspection program. API 580 describes the key elements of an RBI process as management systems for maintaining documentation, personal qualifications, data requirements, and analysis updates; a method for determining the probability of failure; a method for determining the consequence of failure; and a methodology for managing risk through inspection and other mitigation activities. The methodology proposed in this paper was based on the steps listed in the API 580 document.

The TWI research report of Wintle et al. [5] contains a very detailed description of the risk-based inspection methodology and best practices. The report views RBI as one of a range of methodologies within the wider process of plant integrity management. It focuses on the form and management of the RBI process rather than on specific techniques or approaches. It highlights the importance of the multidisciplinary team approach to RBI and the role of the competent person. It shows how, as a result of risk assessment, examination intervals could be extended for some items of equipment.

\section{PROPOSED MODEL}

The proposed risk-based model for the operation and maintenance of non-metallic items of a process plant was broken down into the standard three steps of a risk assessment:

- $\quad$ Estimate the probability of an item's failure

- Estimate the consequence of the failure

- Determine the overall risk of failure from probability and consequence estimates

A qualitative approach was followed, where the critical factors influencing risk were defined in terms of a number of matrices. The designation categories for equipment degradation are listed in Table 1. 


\begin{tabular}{|c|c|c|}
\hline Category & Description & Value \\
\hline Poor & Very high degradation probability & 5 \\
\hline Moderate & High degradation probability & 4 \\
\hline Good & Average degradation probability & 3 \\
\hline Very good & Low degradation probability & 2 \\
\hline Excellent & Very low degradation probability & 1 \\
\hline
\end{tabular}

Table 1: Designation categories

Categories ranged from excellent to poor, with a number associated with each category. Owing to the fact that some aspects may have contributed less to failures than others, it was necessary to associate weights with each factor to determine the overall risk of failure associated with the equipment. A brief discussion of all the factors that were used to evaluate the probability and consequence of a failure of a specific asset or item is given in the following sections. A more detailed discussion of all these factors is given by Viviers [6].

\subsection{Evaluation of the probability of failure}

The probability of failure analysis comprises nine sections, each section containing one or more tables or matrices representing various factors that should be considered to determine the probability of a failure occurring. An indicator for the probability of failure is estimated for the nine factors, and is discussed in the following paragraphs.

\subsubsection{Manufacturer quality rating}

"The probability of failure of equipment in critical services will dramatically decrease with an increase in the ability of the manufacturer to consistently deliver equipment meeting customer and regulatory requirements". A company with an ISO 9001:2000 quality management system in place should have proven records of the basic knowledge and experience associated with producing a quality product. If the manufacturer is unknown, and has no quality systems or quality procedures in place, the probability of failure associated with the equipment supplied by this company will be higher. The rating for 'manufacturer quality' is shown in Table 2.

\subsubsection{Equipment history and previous inspection records}

Previous history in many cases is the most determining factor for making decisions about the probability that a piece of equipment will fail within a certain period. If a tank has been in operation for ten years and shows no sign at all of degradation, there should be a very good possibility that the vessel will be good for the next ten years, provided that the operating conditions stay the same. Previous history should indicate previous problems and repairs done on the equipment. Repairs are normally a result of excessive degradation of the equipment either in a specific localised area or over a larger area of the equipment. 


\section{Description}

No quality management system. No previous track records.

No quality management system.

Some records of previous installations.

No ISO 9001:2000 certification. Quality management system in place. No records of previous installations.

No ISO 9001:2000 certification. Quality management system in place. Reliable records of previous installations.

2

ISO 9001:2000 certification.

Reliable records of previous installations.

Table 2: Evaluation of manufacturer quality rating

Composite materials, unlike thermoplastic materials or steel, can be restored to their initial condition by added layers in the corrosion barrier or structural sections. (This will be covered in more detail during the internal and external corrosion factors.) The first factor that will be considered is associated with the notion that the history of the piece of equipment can be traced. The more information is available, the more accurate the probability for failure estimation. If no information is available, the current status of the equipment will be the only determining factor. It will not be possible to determine the degradation rate from previous history. The equipment history indicator is estimated from manufacturers' records and inspection records, as shown in Table 3 . Inspection records and manufacturing data are legally required for pressure vessels, but not mandatory for non-pressurised systems.

Description

No manufacturing records exist. No inspection records exist.

No manufacturing records exist.

Limited inspection records exist.

No manufacturing records exist.

Comprehensive inspection records exist.

Comprehensive manufacturing records exist.

Limited inspection records exist.

Very comprehensive manufacturing records exist.

Very comprehensive inspection records exist.

\section{Equipment history} rating

5

4

Table 3: Evaluation of equipment history 


\subsubsection{Equipment age and number of recorded repairs}

Two aspects are covered in this section. The first is the length of time that the specific equipment has been operated. Degradation of equipment normally happens over a period of time at a specific rate. The longer the equipment has been in operation, the higher the probability of degradation, and thus the higher the probability of failures. In general, composite materials will lose some of their properties over long periods of time. This will be especially important when an underground pipeline is considered. Normally pipes are subject to extensive cyclic loads over their lifetime. Tests are normally carried out to determine the long-term behaviour of pipelines over a period of fifty years. For normal storage tanks, this phenomenon may not play a major role during the design phase of the project. The probability indicator values related to the age of the equipment are given in Table 4.

\begin{tabular}{|cc|} 
Description & Equipment age rating \\
\hline Time in operation $>15$ years & 5 \\
\hline Time in operation 11-15 years & 4 \\
\hline Time in operation $4-10$ years & 3 \\
\hline Time in operation $1-3$ years & 2 \\
\hline Time in operation $<1$ year & 1 \\
\hline
\end{tabular}

Table 4: Evaluation of equipment age

\subsubsection{Visual inspection rating}

Composite materials are normally transparent to some degree, allowing the competent inspector to see much more, compared with metallic materials. Metallic materials in general are not transparent, and defects can only be seen with methods such as radiography. However, with composite-material vessels, various defects cracks, for example - can be detected through visual inspection. One of the main factors that was considered was the inspector's ability to gain access to the inside and the outside of the equipment. A $100 \%$ visual inspection indicates that a $100 \%$ internal and external inspection is possible. If the equipment can be fully inspected externally, but no access is possible for an internal inspection, this should be rated according to the amount of information available from the external inspection. Normally this will not reveal any information on the condition of the corrosion barrier, and should thus be given a lower rating. The probability indicator values relating to visual inspection are given in Table 5 .

\subsubsection{Medium rating}

Generally the most important aspect when designing or manufacturing a new piece of equipment is the material selection process. Material selection is dependent on various aspects, such as the medium or environment in which the equipment will be operating, and the temperature and the pressures at which the equipment will operate. Normally the first step would be to obtain the process datasheet for the 
equipment from the process engineers. From this all the data could be obtained to make a material selection. However, no matter how accurate the material selection process, all material does degrade with time.

\begin{tabular}{|cc|}
\hline Description & $\begin{array}{c}\text { Visual inspection } \\
\text { rating }\end{array}$ \\
\hline No visual inspection possible & 5 \\
\hline $20 \%$ visual inspection possible & 4 \\
\hline $50 \%$ visual inspection possible & 3 \\
\hline $80 \%$ visual inspection possible & 2 \\
\hline $100 \%$ visual inspection possible & 1 \\
\hline
\end{tabular}

Table 5: Evaluation of inspection possibilities

The first determining factor will be the nature of the data that exists on the piece of equipment or pipeline's expected degradation when in contact with a specific medium. The more data available, the more accurately the probability of degradation can be determined. If no data exists, one will probably not be able to classify the equipment's 'medium rating'. In such a case the highest risk profile for this category will be associated with it. The indicator values for rating the amount of data available on the medium are given in Table 6.

\begin{tabular}{|c|c|}
\hline Description & $\begin{array}{l}\text { Medium data } \\
\text { rating }\end{array}$ \\
\hline $\begin{array}{l}\text { No data is available on the medium, and } \\
\text { no previous history exists }\end{array}$ & 5 \\
\hline $\begin{array}{c}\text { No data is available on the medium, } \\
\text { but previous history exists }\end{array}$ & 4 \\
\hline $\begin{array}{l}\text { Medium is a combination of chemicals, } \\
\text { all of whose concentrations are unknown }\end{array}$ & 3 \\
\hline $\begin{array}{l}\text { Medium is a combination of chemicals, } \\
\text { all of whose concentrations are known }\end{array}$ & 2 \\
\hline $\begin{array}{l}\text { Medium is a single chemical } \\
\text { whose concentration is known }\end{array}$ & 1 \\
\hline
\end{tabular}

Table 6: Influence of medium

\subsubsection{Temperature rating}

Excessively high temperature and temperature shocks are the biggest problem areas for non-metallic materials in process plants. Composite materials consist of both glass (reinforcement) and resin (matrix). Glass is able to withstand very high temperatures, and so heat is not a limiting factor. However, the resin matrix cannot withstand very high temperatures. For composite materials, the heat distortion 
temperature (HDT) of the resin is normally provided by the suppliers. With metallic materials the allowable stress of the material reduces when temperature increases. The same principle applies to both composite and thermoplastic materials. For the purpose of determining the probability of degradation due to temperature, the closer the equipment is operating to the HDT of the specific resin, the higher the probability of failure. This is a factor considered by the design codes for composite piping and vessels provided by the British Standards Institute [7], [8], and [9]. The indicator values used for evaluating the temperature rating are given in Table 7.

\begin{tabular}{|cc|}
\hline Operating temperature & Temperature rating \\
\hline HDT & 5 \\
\hline HDT $-20^{\circ} \mathrm{C}$ & 4 \\
\hline $\mathrm{HDT}-30^{\circ} \mathrm{C}$ & 3 \\
$\mathrm{HDT}-40^{\circ} \mathrm{C}$ & 2 \\
\hline $\mathrm{HDT}-50^{\circ} \mathrm{C}$ or more & 1 \\
\hline
\end{tabular}

Table 7: Influence of temperature

\subsubsection{Internal condition rating}

The corrosion rate for glass reinforced plastics (GRP) is not easy to determine, since it is very difficult to determine the thickness of the material on- or off-line. The thickness could be measured with a polygauge; but this thickness tester requires access to the inside of the vessel or equipment, which is not always possible. Secondly, GRP is a non-homogenous material, meaning that it is constructed in layers of materials that differ in different cross-sections or thickness. GRP is normally constructed with a corrosion barrier on the inside area of the equipment that will be in contact with the medium. The corrosion barrier is defined as a resinrich area (>70\% resin), made with a high quality resin that will provide excellent corrosion resistance against the medium. The 'corrosion rate' will be very low initially, but when the corrosion barrier is lost, the degradation rate will increase and the risk to operations will thus also increase. The indicator values associated with internal condition and corrosion are given in Table 8.

\subsubsection{External condition rating}

External corrosion or damage could also contribute to the degradation rate of equipment, and thus increase the probability of failure. External chemical corrosion is normally a result of chemical spills or drips on to the vessel. Storage tanks with open tops could also overflow, causing chemical attack on the outside of a vessel. External corrosion should be taken into consideration if the equipment or piping is installed underground. With underground installation, soil contamination may cause external corrosion. Ultraviolet (UV) degradation is usually experienced on the outside of equipment, which for obvious reasons is also more susceptible to impact damage. 


\section{Internal corrosion barrier rating}

\begin{tabular}{cccccc}
$\begin{array}{c}\text { Indications } \\
\text { Cracks }\end{array}$ & $\begin{array}{c}\text { Major } \\
\text { indications }\end{array}$ & $\begin{array}{c}\text { Moderate } \\
\text { indications }\end{array}$ & $\begin{array}{c}\text { Small } \\
\text { indications }\end{array}$ & $\begin{array}{c}\text { Very small } \\
\text { indications }\end{array}$ & $\begin{array}{c}\text { No } \\
\text { indications }\end{array}$ \\
$\begin{array}{c}\text { Resin } \\
\text { starvation }\end{array}$ & 5 & 4 & 3 & 2 & 1 \\
$\begin{array}{c}\text { Signs of } \\
\text { loose fibres }\end{array}$ & 5 & 4 & 3 & 2 & 1 \\
$\begin{array}{c}\text { Glass fibres } \\
\text { visible }\end{array}$ & 5 & 4 & 3 & 2 & 1 \\
$\begin{array}{c}\text { Discoloration } \\
\text { Impact }\end{array}$ & 5 & 4 & 3 & 2 & 1 \\
$\begin{array}{c}\text { damage } \\
\text { Erosion }\end{array}$ & 5 & 4 & 3 & 2 & 1 \\
$\begin{array}{c}\text { Delamination } \\
\text { Chemical }\end{array}$ & 5 & 4 & 3 & 2 & 1 \\
attack & 5 & 4 & 3 & 2 & 1 \\
\hline Other & 1 & 1 & 3 & 2 & 1 \\
\hline
\end{tabular}

Table 8: Evaluation of internal corrosion factors

\begin{tabular}{cccccc}
\hline $\begin{array}{c}\text { Indications } \\
\text { Cracks }\end{array}$ & $\begin{array}{c}\text { Major } \\
\text { indications }\end{array}$ & $\begin{array}{c}\text { Moderate } \\
\text { indications }\end{array}$ & $\begin{array}{c}\text { Small } \\
\text { indications }\end{array}$ & $\begin{array}{c}\text { Very small } \\
\text { indications }\end{array}$ & $\begin{array}{c}\text { No } \\
\text { indications }\end{array}$ \\
\hline $\begin{array}{c}\text { Resin } \\
\text { starvation }\end{array}$ & 5 & 4 & 3 & 2 & 1 \\
$\begin{array}{c}\text { Glass fibres } \\
\text { visible }\end{array}$ & 5 & 4 & 3 & 2 & 1 \\
\hline $\begin{array}{c}\text { Discoloration } \\
\text { Impact }\end{array}$ & 5 & 4 & 3 & 2 & 1 \\
$\begin{array}{c}\text { damage } \\
\text { Erosion }\end{array}$ & 5 & 4 & 3 & 2 & 1 \\
\hline $\begin{array}{c}\text { Delamination } \\
\text { Chemical }\end{array}$ & 5 & 4 & 3 & 2 & 1 \\
attack & 5 & 4 & 3 & 2 & 1 \\
\hline $\begin{array}{c}\text { UV } \\
\text { degradation }\end{array}$ & 5 & 4 & 3 & 2 & 1 \\
Other & 1 & 1 & 3 & 2 & 1 \\
\hline
\end{tabular}

Table 9: Evaluation of external corrosion factors

In many cases the RBI process is recommended for equipment that has a proven record of a very low or no degradation rate. A decision will therefore be made if the equipment can only be inspected at five-year or even ten-year intervals. The longer 
the inspection interval required, the more detailed the risk analysis that should be performed. The failure probability indicator values for the 'external condition' of the equipment are given in Table 9.

\subsubsection{Mechanical and fatigue rating}

The RBI process for steel is very well defined in terms of mechanical failure mechanisms and fracture mechanics. In most instances a crack in metallic equipment can be analysed to obtain the crack growth rate, and thus the possibility that it may lead to a failure. This aspect is still a grey area in the case of nonmetallic equipment - although some of the mechanisms causing mechanical damage or fatigue damage also apply to non-metallic equipment.

Stress raisers in the form of sharp edges will cause a higher degradation area in the equipment. High stress areas could include attachments, residual stress areas, loads on flanges as a result of bolt torques, and thermal stresses. Cracking is a typical failure mode in high stress areas. Areas in equipment with no or very low flow will generally have increased corrosion rates. It is therefore always important to identify the worst-case areas and to use these as the determining factor when analysing the probability of equipment failures. GRP is a more brittle material by nature, and any loadings as a result of vibration could cause failure if installed incorrectly. Vibration is normally caused by nearby rotating machinery such as pumps, but it could also be a result of turbulent flow in a pipeline where the pipe is not correctly supported. Another factor that could lead to catastrophic failures is changes in the specific gravity (SG) of the medium as a result of new operating conditions.

Many parameters could be discussed under this heading, and considerations should definitely not be limited to the criteria provided in Table 10. The worst-case probability indicator should always be used when deciding on a specific rating for equipment.

\subsubsection{Overall probability of failure indicator}

A probability rating for an item in a plant is calculated from the nine sections outlined above. Since the contribution of each of these sections towards an overall probability of failure is not the same, weight factors have to be allocated for each section. An indicator value for the overall probability of failure is given by equation 1.

$P_{\text {overall }}=\sum_{i=1}^{9} P_{i} \cdot W_{i}$

In equation 1 , the probability indicator values $P_{i}$, are the values obtained for the nine sections discussed above. The weight factors $W_{i}$ that were proposed for a process plant are given in Table 11. A risk team should decide on the weight factors for each type of plant. 


\begin{tabular}{|c|c|c|c|c|c|}
\hline \multirow[b]{2}{*}{ Indications } & \multicolumn{5}{|c|}{ Mechanical damage and fatigue rating } \\
\hline & $\begin{array}{l}\text { Very high } \\
\text { probability }\end{array}$ & $\begin{array}{l}\text { Moderate } \\
\text { probability }\end{array}$ & $\begin{array}{c}\text { Small } \\
\text { probability }\end{array}$ & $\begin{array}{l}\text { Very small } \\
\text { probability }\end{array}$ & $\begin{array}{c}\text { No } \\
\text { probability }\end{array}$ \\
\hline Vibrations & 5 & 4 & 3 & 2 & 1 \\
\hline Turbulent flow & 5 & 4 & 3 & 2 & 1 \\
\hline $\begin{array}{l}\text { Incorrect } \\
\text { supports }\end{array}$ & 5 & 4 & 3 & 2 & 1 \\
\hline $\begin{array}{l}\text { SG exceeding } \\
\text { design value }\end{array}$ & 5 & 4 & 3 & 2 & 1 \\
\hline $\begin{array}{l}\text { Over-torque } \\
\text { on flanges }\end{array}$ & 5 & 4 & 3 & 2 & 1 \\
\hline $\begin{array}{l}\text { Excessive } \\
\text { bending } \\
\text { moments }\end{array}$ & 5 & 4 & 3 & 2 & 1 \\
\hline $\begin{array}{l}\text { Unexpected } \\
\text { dead weights }\end{array}$ & 5 & 4 & 3 & 2 & 1 \\
\hline $\begin{array}{l}\text { Thermal } \\
\text { stresses }\end{array}$ & 5 & 4 & 3 & 2 & 1 \\
\hline Over-pressure & 5 & 4 & 3 & 2 & 1 \\
\hline Stress raisers & 1 & 1 & 1 & 1 & 1 \\
\hline Cyclic loadings & 1 & 1 & 1 & 1 & 1 \\
\hline Other & 5 & 4 & 3 & 2 & 1 \\
\hline
\end{tabular}

Table 10: Evaluation of mechanical damage and fatigue

\begin{tabular}{|cc|}
\hline Risk factor & Weight (\%) \\
\hline Manufacturer quality & 5 \\
\hline Equipment history & 10 \\
\hline Equipment age & 5 \\
\hline Inspection methods & 10 \\
\hline Process medium & 10 \\
\hline Process temperature & 20 \\
\hline Internal condition & 15 \\
\hline External condition & 15 \\
\hline Mechanical \& fatigue & 15 \\
\hline
\end{tabular}

Table 11: Proposed weight factors for process plants 


\subsection{Determining the consequence of failure}

'Consequence of failure' analysis deals with the actual effect that a failure will have on people, the environment, and production. Any of the methods describe in the literature may be used for the consequence analysis. Only the most common aspects are included in the consequence analysis proposed in this paper.

\subsubsection{Safety consequence}

The first consequence to be considered is safety. Safety is non-negotiable, and the main reason for the risk management process. Safety is not only a way of life but also a legal requirement that applies to natural persons and business entities. Safety consequences could range from an injury requiring first aid to the loss of life. The following factors were included for evaluating the safety consequences:

- Health

- $\quad$ Pressure (energy)

- Toxic nature

- Affected area

- Volume

- $\quad$ Liquid or gas

- Injuries and fatalities

- Flammability

Indicator values for the safety consequence factors are given in Table 12.

\begin{tabular}{|ccccccc|}
\hline & \multicolumn{5}{c}{ Safety consequence factor } \\
\hline Indications & $\begin{array}{c}\text { Very } \\
\text { high }\end{array}$ & High & Moderate & Low & Very low \\
\hline Health risk & 5 & 4 & 3 & 2 & 1 \\
\hline Pressure & 5 & 4 & 3 & 2 & 1 \\
\hline Toxic nature & 5 & 4 & 3 & 2 & 1 \\
\hline Affected area & 5 & 4 & 3 & 2 & 1 \\
\hline Volume & 5 & 4 & 3 & 2 & 1 \\
\hline Liquid or gas & 5 & 4 & 3 & 2 & 1 \\
\hline Injuries & 5 & 4 & 3 & 2 & 1 \\
\hline Flammability & 5 & 4 & 3 & 2 & 1 \\
\hline Isolation rate & 5 & 4 & 3 & 2 & 1 \\
\hline
\end{tabular}

Table 12: Influence of safety consequence

\subsubsection{Environmental consequence}

Environmental consequence has become increasingly important in recent years. Protection of the environment has become a global focus, and related legislation 
will become more stringent in the future. The detail of the analysis will be dependent on company policies and applicable legislation. The three main aspects that were considered are the toxic nature of the medium, the level of contamination, and the dispersal rate - and thus the volume and area affected by the failure. The toxic nature in this case should be analysed in terms of the effect on the environment rather than the effect on people. The level of contamination refers to the cleanup procedures and methods. The contamination might affect a very small area, or it might have a wider effect, such as ground water contamination. The last aspect considered is the dispersal rate, referring to the volume of medium introduced into the environment. Indicator values for the environmental consequence are given in Table 13.

\begin{tabular}{|c|c|c|c|}
\hline & Toxic nature & $\begin{array}{c}\text { Level of } \\
\text { contamination }\end{array}$ & Dispersal rate \\
\hline Very high & 5 & 5 & 5 \\
\hline High & 4 & 4 & 4 \\
\hline Moderate & 3 & 3 & 3 \\
\hline Low & 2 & 2 & 2 \\
\hline Very low & 1 & 1 & 1 \\
\hline
\end{tabular}

Table 13: Influence of environmental consequence

\subsubsection{Production consequence}

The production consequence mainly takes into account the money lost as a result of a failure. In cases where an exact value cannot be determined, one should make a reasonable estimate. The repair rate represents the time from shutdown to the time when the equipment is totally restored and returns to $100 \%$ production capability. This could range from a couple of hours to weeks or months, depending on the severity and type of equipment affected. The criticality of the unit or equipment refers to the fact that in some instances the plant can still operate owing to the low criticality of the equipment in question. In some instances, raw product can be obtained from external sources, bypassing the affected area. In highly critical equipment, the failure will result in a total shutdown of the plant, and this will maximize the production consequence. The cost of repair should be taken into account - along with the cost of replacement, should this be necessary to ensure the integrity of the equipment. Indicator values for production consequence are given in Table 14.

\subsubsection{Overall consequence of failure indicator}

The overall consequence of failure is a function of the safety, environmental, and production consequences. The indicator for overall consequence is calculated using equation 2. 
$C_{\text {overall }}=\sum_{j=1}^{3} C_{j} \cdot W_{j}$

In equation 2 , the consequence factors $C_{j}$ are the values obtained for the three aspects that were included in the model - safety, environment, and production. Weight factors for the consequence of failure $W_{j}$ are proposed for each aspect, since different systems (plants) might necessitate different emphases. One plant might process products that represent a large environmental hazard (e.g. a nuclear plant), while another plant might represent a high safety hazard (e.g. an oil rig). The weight factors proposed for process plants are given in Table 15.

\begin{tabular}{|cccccc} 
& \multicolumn{5}{c}{ Production consequence } \\
\hline Indications & Very high & High & Moderate & Low & Very low \\
\hline Repair rate & 5 & 4 & 3 & 2 & 1 \\
\hline Criticality of unit & 5 & 4 & 3 & 2 & 1 \\
\hline Cost of repair & 5 & 4 & 3 & 2 & 1 \\
\hline Cost to replace & 5 & 4 & 3 & 2 & 1 \\
\hline
\end{tabular}

Table 14: Influence of production consequence

\begin{tabular}{lcc} 
& Consequence factor & Weight (\%) \\
\hline Safety & 50 \\
Environmental & 25 \\
\hline Production & 25
\end{tabular}

Table 15: Weight factors for calculating overall consequence for a process plant

\subsection{Determining the overall risk of failure}

An indicator for the overall risk for an item or component, $R_{\text {overall }}$, can be calculated as the product of the indicators for probability of failure and consequence of failure. The overall probability indicator from equation 1 and the overall consequence indicator from equation 2 are therefore used to calculate an indicator for overall risk with equation 3 below.

$R_{\text {overall }}=P_{\text {overall }} \times C_{\text {overall }}$

A graphic illustration of the overall risk for a technical system can be obtained by plotting the probability and consequence indicator values for various subsystems on a risk map or risk matrix. The proposed risk matrix, shown in Figure 1 , is the standard $5 \times 5$ matrix used by the API 580 standard for RBI. 


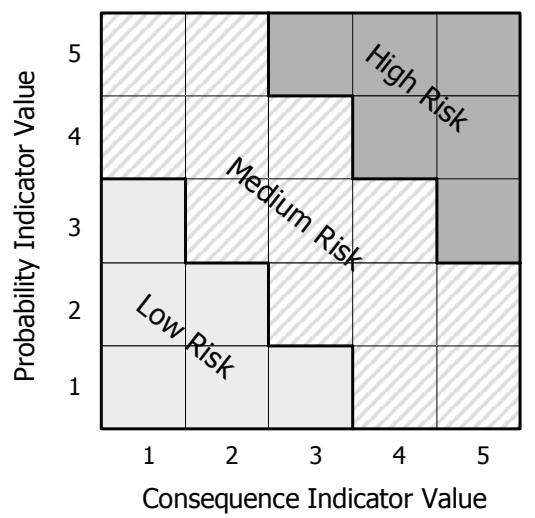

Figure 1: Risk plot for failure of non-metallic items

The process up to this point has included all the factors that could contribute to the probability or consequence of a failure. Estimating an indicator value for the actual risk of operation of the equipment is done to prioritise and distinguish between high, medium, and low risk equipment. Depending on the plant policies, mitigation procedures or actions should now be implemented to reduce the risk of the equipment so that it falls in the 'low risk' or (at most) the 'medium risk' area. The overall risk indicator value should be determined mathematically, and acceptance levels should be established by the company. The overall risk indicator value can also be used to identify the most critical equipment, and to focus management effort to mitigate these critical risks before attention is given to lesser risks.

\section{CONCLUSION}

A new model and approach to risk assessment of non-metallic equipment of a process plant has been developed and tested. Details of two case studies that are not discussed in this paper are given by Viviers (5). Breaking the model down into various matrices covering different aspects that affect the risk of operation proved to be the most appropriate way of assessing the risk of non-metallic equipment. It was concluded that non-metallic materials degrade differently from metallic materials, and what is normally included in the probability of failure assessment for metallic materials cannot be applied directly to non-metallic materials. A step-bystep approach was followed to determine an indicator for the probability of failure of non-metallic materials. It was decided to make use of a qualitative approach for the risk management process, as a full quantitative approach is time-consuming and requires detailed information - it is difficult to implement if comprehensive data on the equipment does not exist. The qualitative approach also allowed a degree of freedom in allocating different ratings based on general knowledge and experience rather than on exact numbers.

The proposed model contains practical application of years of experience in the development of specifications related to non-metallic materials. The model can be 
applied in general to enable engineers to prioritise equipment in terms of associated risk, to enable the development of risk mitigation and inspection procedures. The application of various criteria and possible degradation mechanisms could also be useful to the materials engineer who does not have a great deal of knowledge of non-metallic materials.

The main limitation of the model is the fact that it is based on composite materials only. Much of the non-metallic equipment in process plants is manufactured from thermoplastic materials or from a combination of thermoplastic and composite materials. The same basic principles can be used - although the model would have to be expanded to include the typical indications that could be expected from thermoplastic materials. The model for composite materials can still be applied, even if very little information is available on the history of the equipment.

\section{REFERENCES}

[1] Department of Labour. 1993. Occupational Health and Safety Act (Act No. 85 of 1993, Section 43). South Africa.

[2] Department of Labour. 2004. Government Gazette, Vol 471, Notice of Draft Amendment: Pressure Equipment Regulations.

[3] Tae-Gu, K., Jeong-Hie, K., Young-Dal K. and Kwang-Ill, K. 2002. Current risk management status of the Korean petrochemical industry. Journal of Loss Prevention in the Process Industries, 15, pp. 311-318.

[4] API 580. 2000. Recommended practice. $1^{\text {st }}$ edition. API Publishing Services, Washington.

[5] Wintle J.B., Kenzie B.W., Amphlett G.J. and Smalley S. 2001. Best practice for risk based inspection as a part of plant integrity management. TWI and Royal \& Sun Alliance Engineering for the health and safety executive, Her Majesty's Stationary Office, Norwich.

[6] Viviers, J.J. 2005. Risk Management (RBI) Methodology for Non-Metallic Process Plant Equipment. MSc project report, University of Pretoria, 2005.

[7] British Standards Institute. BS 4994. 1987. Design and construction of vessels and tanks in reinforced plastics. London.

[8] British Standards Institute. BS 7159. 1989. Design and construction of glass reinforced plastic (GRP) piping systems for individual plants or sites. London.

[9] British Standards Institute. BS 6464. 1984. Reinforced plastic pipes, fittings and joints for process plants. London. 